\title{
United States of America
}

\section{"Google v. Oracle"}

\section{Decision of the Supreme Court of the United States}

5 April 2021 - Case No. 18-956

Google LLC v. Oracle America, Inc.

Copyright Act, $\$ 107$

(C) Max Planck Institute for Innovation and Competition, Munich 2021

Keywords Fair use - Software - Java - Lines of code · Copyrightability · Transformative use $\cdot$ Substantiality

1. The copying of only those lines of code, part of an Application Programming Interface (API), that are needed to allow programmers to put their accrued talents to work in a new and transformative program constitutes a fair use of that copyright-protected work.

Publisher's Note Springer Nature remains neutral with regard to jurisdictional claims in published maps and institutional affiliations. 